\title{
STIMULATION OF INNOVATIVE BEHAVIOR THROUGH THE INCLUSIVE LEADERS AND ENGAGED WORKERS
}

\author{
Adil MANSOOR ${ }^{1}{ }^{1} 2^{*}$, Sazali ABDUL WAHAB ${ }^{1}$, Sarwat JAHAN@3 \\ ${ }^{1}$ Putra Business School, University of Putra Malaysia, Seri Kembangan 43400, Malaysia \\ ${ }^{2}$ Faculty of Management Sciences, Ilma University, Karachi, Pakistan \\ ${ }^{3}$ Department of Business and Accountancy, Lincoln University College, Petaling Jaya 15050, Malaysia
}

Received 13 August 2020; accepted 27 May 2021

\begin{abstract}
Based on social exchange theory, this research introduced a model to understand factors that contribute towards inclusive leadership (IL) and its effect on innovative work behavior (IWB) with employee engagement (EE) as a mediator. Although the connection between IL and IWB is previously established. However, few studies have tested the potential mediation effect of EE particularly in the IT sector. Therefore, this investigation provides new insights as to how IL stimulates the innovation through the meditating impact of EE. Data collected through questionnaire were then analyzed through structural equation modeling. 116 participants have provided the data for this study. We found a positive association of IL with IWB, while the mediating effect of EE was also empirically established. This study is novel because it explained how IL can persuade their subordinates to exhibit positive behavioral outcome (i.e. IWB). Furthermore, the current study also might help the policymakers to devise effective leadership training programs so that their managers may adopt IL style and make the employees more engaged and innovative.
\end{abstract}

Keywords: inclusive leadership, employee engagement, innovative work behavior, IT sector, creativity.

JEL Classification: M12, O36.

\section{Introduction}

Today's era of intense competition has made it essential for organizations to stay competitive and innovative as compared to their rival firms. This can be achieved through an engaged and innovative workforce. Organizational innovation highly depends on the employees' innovative work behavior (IWB) and it provides a competitive advantage to the firms (Mansoor et al., 2020). Employees' IWB includes development, promotion, and implementation of novel ideas (Janssen, 2000). IWB is an extra role behavior of employees that is practiced in the turbulent business environment. Therefore, new challenges can be effectively met in a dynamic environment (Scott \& Bruce, 1998). Agarwal (2014) found that the organizations are very much inclined to discover antecedents of employees' IWB. Scholars have highlighted multiple antecedents of IWB at organizational levels. It was discovered that the organizational innovation can only be achieved through the inclusion of innovative workers.

Leadership is perceived to be among the most pivotal factor in the stimulation of creativity and innovative behavior within the organizations (Khan et al., 2020). IWB requires considerable support from the leadership due to its complex nature. Moreover, it is a non-routine behavior of employees in which they usually avoid traditional thinking (Kessel et al., 2012). Leadership is a key variable that can hinder or enhance IWB (Hughes et al., 2018). The inclusive leadership (IL) ensures accessibility, openness and availability for their workers (Carmeli et al., 2010). Furthermore, inclusive leaders involve the people in decision making and provide them with the opportunities to think and implement creative ideas without the fear of consequences (Mansoor et al., 2020). Therefore, the current study explores how IL promotes employees' IWB, especially in the Pakistani IT sector.

Drawing upon Social Exchange Theory, the current research tries to explore the reciprocal relationship of workers and their inclusive leaders. Different scholars have argued that the leaders persuade their followers by making them more engaged in the workplace (Azim et al., 2019). On the other hand, Al-Ajlouni (2020) found that employee engagement (EE) plays its role in making the workers

*Corresponding author. E-mail: adilmansoor5@gmail.com 
more innovative. EE is considered a critical success factor particularly in the service sector organizations, because engaged staff can better serve the needs of the customers (Nazir \& Islam, 2017). Recently, researchers have identified the need to further explore the possible impact of EE on leadership-innovation relationship (Karatepe \& Olugbade, 2016). Therefore, the current investigation posits that the EE can possibly mediate the association of IL and IWB. This study has two research questions.

RQ1: How does IL promote the innovation among their employees?

RQ2: Does EE mediate the relationship of IL and IWB?

To contribute to the existing literature, this study provides useful insights regarding how IL promotes employees' IWB. It tries to unearth which practices and measures are required to persuade the employees so that they can make the firm successful through innovative ideas. Additionally, this investigation explains how a leader can stimulate innovation among their workforce. Besides, this research has also explored the mediation effect of EE, which enriches leadership literature by identifying the IL as an antecedent of EE. Lastly, drawing upon social exchange theory, this investigation tries to explore the role played by IL in the promotion of IWB through the development of EE. This will further enhance the understanding of policymakers regarding the suitable leadership style required to stimulate employees' IWB.

\section{Review of literature and development of hypotheses}

\subsection{Inclusive leadership and innovative work behavior}

In today's business world, stimulation of innovative behavior is considered as the most important function of the leadership (Amin et al., 2018; Hakimian et al., 2016). IL is vital to create a climate for innovation within the organizations, which ultimately promotes IWB of workers (Ashikali et al., 2020). The leader, who follows the inclusion approach, would engage their followers in the goal development process. Additionally, inclusive leaders would also ensure the availability of all the resources required to achieve the firm's objectives (Khan et al., 2020). Agarwal (2014) identified the important role played by IL in making the employees innovative and creative. The inclusion of employees in the key decision making enhances their ability to perform.

Hollander (2012) explained that IL encourages its followers to become risk-takers, as this would lead towards the implementation of novel ideas. As a result, employees present and implement their ideas without the fear of consequences. Javed et al. (2017) conducted research in the Pakistani textile industry and found that the IL significantly promotes IWB. Similarly, Mansoor et al. (2020) identified that the culture of inclusion created by the inclusive leaders stimulates the employees' innovation. Therefore, this research posits the following hypothesis:
Hypothesis 1: IL positively influences the employees' IWB.

\subsection{Inclusive leadership and employee engagement}

Recently, EE has gained a lot of attention from practitioners and academicians (Chen et al., 2020; Zheng et al., 2020). Several organizational outcomes depend largely on the EE (Bakker \& Albrecht, 2018); hence, this became the primary reason for continued interest from various scholars. Therefore, organizations are striving to develop and retain engaged workers so that they could help the organizations to gain success in the turbulent business environment. Moreover, IL offers a encouraging work environment that develops extra role behavior such as EE (Choi et al., 2015). Wang et al. (2019) conducted a study on Chinese nurses and found that the IL positively promotes their level of engagement with the work. Similarly, Cenkci et al. (2020) found that the workers' engagement depends largely on the inclusiveness and fair dealing of organizational leaders. Based on these arguments, we posit the hypothesis as under:

Hypothesis 2: IL positively influences the EE.

\subsection{Employees' IWB and employee engagement}

The full commitment of the workers to perform their job tasks refers to the EE. Therefore, EE is directly associated with the job commitment. Likewise, it was empirically established that the empowered employees become more engaged with their work, as workers perceive that they are trusted by their top management. This positive perception makes the workers more loyal and committed to the firms. Resultantly, they are much more inclined to stick with the company and keep doing better. Furthermore, it was also found that the EE becomes an antecedent of IWB (L. Miller \& A. F. Miller, 2020). Similarly, a study conducted by Al-Ajlouni (2020) found that the employees exhibit IWB when they were more engaged with their job. So, this research posits the following hypothesis:

Hypothesis 3: EE positively influences the employees' IWB.

\subsection{Mediating effect of employee engagement}

IL shows accessibility to their followers to make them more engaged in decision making and goal setting. Inclusive leaders not only involve the workers in decision making, but they also appreciate the input received from them. Nembhard and Edmondson (2006, p. 948) mentioned this as "their voices are generally valued". The positive perception created through IL would certainly enhance the commitment level of individuals. Carmeli et al. (2010) categorized IL as one type of relational leadership. Like other relational leadership styles, IL also promotes positive behavior among the workforce.

Lisbona et al. (2018) suggested that the engaged employees demonstrate a higher performance level as compare to those who have less commitment to the 
organization. Likewise, Choi et al. (2015) mentioned that IL generates positive organizational outcomes such as higher performance, EE, and innovation. It was suggested by Lisbona et al. (2018) to further examine the impact of $\mathrm{EE}$ as to how it influences the employees' IWB. Hence, this investigation posits the hypothesis:

Hypothesis 4: The interlinkage of IL and employees' IWB is mediated through EE.

The following theoretical model (Figure 1) is proposed to check the relationship between IL, IWB, and EE.

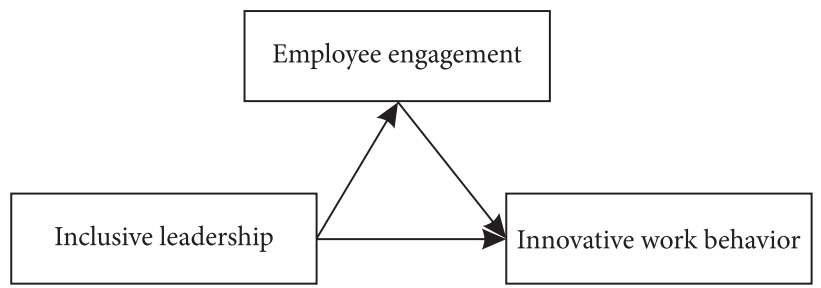

Figure 1. Research model

\section{Methodology of research}

\subsection{Sampling and data collection}

The current investigation has obtained the data from the workers of Pakistani IT firms through the application of cross-sectional research design. These firms are selected due to hyper-competition and complex business environment prevailing in the IT industry, which has made it essential for the organizations to direct their attention towards employees' IWB (Javed et al., 2019).

In order to select the participants, the lead author contacted ten IT firms and explained the purpose and importance of the study. Three firms were agreed to provide data for the research. Therefore, all the questionnaires were sent through online mode because IT professionals may find it more convenient due to their continuous internet usage. Additionally, the COVID-19 pandemic situation made it

Table 1. Demographics

\begin{tabular}{|c|c|c|}
\hline & Frequency & $\%$ \\
\hline \multicolumn{3}{|l|}{ Gender } \\
\hline Male & 84 & 72.41 \\
\hline Female & 32 & 27.59 \\
\hline Total & 116 & \\
\hline \multicolumn{3}{|l|}{ Age } \\
\hline Below 35 & 54 & 46.55 \\
\hline $35-45$ & 39 & 33.62 \\
\hline Above 46 & 23 & 19.83 \\
\hline Total & 116 & \\
\hline \multicolumn{3}{|l|}{ Education } \\
\hline Bachelors & 32 & 27.59 \\
\hline Masters & 84 & 72.41 \\
\hline Total & 116 & \\
\hline
\end{tabular}

more feasible to collect the data online. 150 questionnaires were sent on the official email addresses provided by the human resource department. Finally, 116 responses were included in the data analysis, and 34 responses were rejected due to the incomplete responses. Table 1 provides details regarding the sample.

\subsection{Measures}

We adopted standardized questionnaires for the data collection purpose. Unless otherwise stipulated, a five-point Likert scale was used to measure the dimensions. Employees' perception of IL was assessed through the scale developed by Carmeli et al. (2010). This scale has comprised of nine items. The value of Cronbach alpha was 0.87 . This scale identifies the perception of employees as to what extent they think their managers are exhibiting IL behavior.

IWB was measured through the 9 item scale of Janssen (2000). The value of Cronbach alpha was 0.83 . This scale was also used by Mansoor et al. (2020) in his study. For measuring EE, we used the scale developed by Schaufeli et al. (2006). The responses were obtained through the 7 point Likert scale ranging from "Never $=0$ " to "Always = 6." The Cronbach alpha was 0.81 . Through this scale, the researchers have tried to guage the level of engagement within the employees.

\section{Results}

This investigation has used the structural equation modeling technique through SmartPLS version 3 for testing the proposed hypotheses. Due to its predictive nature, SmartPLS was used in this study (Hair et al., 2017). It also provides more reliable results even when the sample size is small (Henseler et al., 2015).

\subsection{Measurement model}

Table 2 presents Cronbach alpha values, which depict the reliability of the instruments. The values of Cronbach alpha ranged from 0.84 to 0.90 ; therefore, it satisfies the desired level of $>0.70$ as per recommendation of Fornell and Larcker (1981). The values of AVE and Composite reliability have also fulfilled the criteria set by Fornell and Larcker (1981). Thus, we established the composite reliability and convergent validity of the scales.

Table 2. Composite reliability and convergent validity

\begin{tabular}{|l|c|c|c|}
\hline & Cronbach's Alpha & CR & AVE \\
\hline IL & 0.87 & 0.79 & 0.59 \\
\hline IWB & 0.84 & 0.74 & 0.62 \\
\hline EE & 0.90 & 0.83 & 0.67 \\
\hline
\end{tabular}

Note: IL = inclusive leadership; IWB = innovative work behavior; $\mathrm{EE}=$ employee engagement.

Following Henseler et al. (2015) recommendations, values of the Heterotraite-Monotrait ratio of correlation 
(HTMT) were used to determine the discriminant validity of measurement scale. Kline (2015) proposed that the HTMT value should be $<0.85$ for establishing the discriminant validity. Table 3 presents the values of HTMT which are well below the recommended value of less than 0.85 . Thus, it confirms the discriminant validity of the scale.

Table 3. Heterotrait-Monotrait ratio of correlation (HTMT)

\begin{tabular}{|c|c|}
\hline Variables & Values of HTMT \\
\hline IL & 0.53 \\
\hline IWB & 0.61 \\
\hline EE & 0.55 \\
\hline
\end{tabular}

Note: IL = inclusive leadership; IWB = innovative work behavior; $\mathrm{EE}=$ employee engagement.

From the below presented table (Table 4), it can be seen that values of factor loadings are above .70 which establishes convergent validity.

Table 4. Factor loadings

\begin{tabular}{|c|c|}
\hline Construct & Loadings \\
\hline \multicolumn{2}{|c|}{ Inclusive Leadership (IL) } \\
\hline IL 1 & 0.729 \\
\hline IL 2 & 0.744 \\
\hline IL 3 & 0.763 \\
\hline IL 4 & 0.712 \\
\hline IL 5 & 0.722 \\
\hline IL 6 & 0.804 \\
\hline IL 7 & 0.814 \\
\hline IL 8 & 0.835 \\
\hline IL 9 & 0.737 \\
\hline \multicolumn{2}{|c|}{ IWB } \\
\hline IWB 1 & 0.711 \\
\hline IWB 2 & 0.792 \\
\hline IWB 3 & 0.707 \\
\hline IWB 4 & 0.839 \\
\hline IWB 5 & 0.708 \\
\hline IWB 6 & 0.756 \\
\hline IWB 7 & 0.820 \\
\hline IWB8 & 0.741 \\
\hline IWB 9 & 0.866 \\
\hline \multicolumn{2}{|c|}{ Employee Engagement (EE) } \\
\hline EE 1 & 0.914 \\
\hline EE 2 & 0.900 \\
\hline EE 3 & 0.913 \\
\hline EE 4 & 0.694 \\
\hline EE 5 & 0.878 \\
\hline EE 6 & 0.852 \\
\hline EE 7 & 0.746 \\
\hline EE 8 & 0.802 \\
\hline EE 9 & 0.791 \\
\hline
\end{tabular}

\subsection{Structural model}

The bootstrapping procedure was applied to examine the hypothesized theoretical model. Firstly, we test the impact of inclusive leadership on innovative work behavior and employee engagement. Results revealed that inclusive leadership significantly and positively impacts the IWB and EE; therefore, both hypothesis 1 (IL positively influences the employees' IWB) and hypothesis 2 (IL positively influences employee engagement) are accepted. Furthermore, the interlinkage between EE and IWB was also found significantly related. Hence, hypothesis 3 (Employee engagement positively affects the employees' IWB) was also supported. The mediation effect was tested by following the procedure suggested by Nitzl et al. (2016). The indirect impact of inclusive leadership on employees' IWB through EE is significant and positive, but it is reduced in size (Table 5). Therefore, it shows that the EE has partially mediated the association between IWB and IL. Through this, the hypothesis 4 (i.e. The association of IL and IWB is mediated by EE) was also supported.

Table 5. Testing of hypotheses

\begin{tabular}{|l|c|c|c|}
\hline \multicolumn{1}{|c|}{ Relationship } & Beta value & T value & P-value \\
\hline IL -> IWB & 0.54 & 5.35 & 0.00 \\
\hline IL -> EE & 0.49 & 4.90 & 0.00 \\
\hline EE -> IWB & 0.52 & 5.03 & 0.00 \\
\hline IL-> EE -> IWB & 0.39 & 4.52 & 0.00 \\
\hline
\end{tabular}

Note: IL = inclusive leadership; IWB = innovative work behavior; $\mathrm{EE}=$ employee engagement.

\section{Discussion and conclusions}

This investigation aimed to highlight the impact of IL on employees' IWB with the intervening role of EE. All the hypothesized relationships were supported in our study. It was found that the IL promotes IWB among employees and EE mediates this relationship.

The positive association between IL and employees' IWB stresses the need for an inclusive organizational culture for the promotion of innovation. Inclusive leaders involve their subordinates in decision making and keep them abreast of full knowledge related to the organizational goals. As a result, employees come up with the innovative thoughts without the fear of negative consequences. Moreover, IL makes people more confident and they can freely implement their creative ideas. This result also matches with other studies (e.g. Ashikali et al., 2020; Mansoor et al., 2020).

This investigation has also revealed that IL affects the behavior of employees through the intervening role of $\mathrm{EE}$. The mediating role of EE depicts that the employees feel obligated towards their organizations because of the inclusive behavior shown by its leaders. Inclusive leaders promote a culture of cooperation which makes the people more involved with their tasks and organization. Therefore, 
it makes sense that the engaged employees would exhibit positive behavioral outcomes in the form of IWB. Although it is empirically established that the IL positively influences multiple behavioral outcomes; however, scholars (e.g. Younas et al., 2020; Zeng et al., 2020) stressed the need to further explore this relationship through the inclusion of different meditating variables. Hence, this research has responded to the call for research from various scholars and analyzed the mediating role of EE.

This study found that the IL significantly influences employees' IWB and the mediation impact of EE on the IL-IWB relationship was also established. This research has offered valuable insights to the managers of the IT industry in specific and other related industries in general. The exhibition of IL style would enable the firms to become more innovative and competent. Organizational success depends largely on the innovative capabilities of its workers. Therefore, this investigation has identified a suitable leadership style i.e. IL, which may stimulate innovation among their staff. Thus, this research offers both theoretical and practical contributions.

\section{Theoretical implications}

The current investigation has contributed to the literature of leadership by identifying the role of $\mathrm{EE}$ as an intervening variable. Although the effect of IL on employees' IWB is previously established; however, the mediating effect of EE makes it more clear as to how IL stimulates innovation among the workers. Additionally, our research has established the direct association between EE and IL. Therefore, it enhances the understanding of IL style and presents a new perspective to look into this relational leadership style (Uhl-Bien, 2006). Furthermore, this research has established the mediation effect of EE in the IL-IWB relationship. This result may direct the attention of other scholars towards the testing of $\mathrm{EE}$ as a potential intervening variable in the association between IL and other outcomes related with the firm. Finally, this is one of the pioneering study which has explored the relationship of EE, IL, and IWB specifically in the Pakistani IT sector.

\section{Managerial implications}

Hyper-competition has increased the need for the adoption of innovative practices to remain competitive. Leadership encourages employees to become more innovative (Ashikali et al., 2020). Therefore, this research provides several practical implications for the organizational policymakers. First, the managers should demonstrate accessibility to hear the issues faced by the workers. Managers should also make all necessary resources available for the individuals so that the workers could implement their novel ideas. Additionally, this research has revealed that the employees would exhibit IWB when they are encouraged through the IL style. Hence, it is recommended for the supervisors to adopt the necessary elements of IL (i.e. accessibility, openness, and availability).
Secondly, the outcome of this study emphasizes the effective management of human resources, specifically related to the IT industry. This industry requires those workers who possess intensive technical knowledge and potential for coming up with creative ideas. Therefore, this research provides useful insights to conceptualize the effective way of leading those individuals through the concept of IL. Leaders exhibiting IL style would promote a conducive environment in which people can share and implement the creative solutions without the fear of consequences.

Thirdly, we recommend that the top management should promote those IT managers who exhibit IL style. Furthermore, training programs should be initiated to make the managers familiar with IL style. Lastly, this study has highlighted the role of $\mathrm{EE}$ as an important predictor of positive behavioral outcomes. Therefore, organizational policymakers must adopt measures to increase the level of EE. To do so, supervisors should cultivate an environment of openness and make themselves accessible whenever the need for consultation emerge among the employees. In this manner, personnel would perceive that they are important and valued for the organization and this will consequently increase their engagement level.

\section{Limitations of research and directions}

Despite of its contribution, this research also has some potential limitations which would become future directions for other researchers. Our study has collected data from one source i.e. employees. Thus, future studies should collect data from both the managers and employees. Moreover, this research was conducted with small sample size due to the impact of COVID-19 pandemic. Therefore, future research should test this model in a bigger sample size in order to generalize the outcome of their investigation. In addition, intrinsic motivation can also be used as a mediator in the future studies. Lastly, there is a need to test this model across different cultures and industries, as the current study was conducted in the Pakistani IT industry.

\section{Author contributions}

Adil Mansoor and Sazali Abdul Wahab conceived the study and were responsible for the design and development of the data analysis. Adil Mansoor and Sarwat Jahan were responsible for data collection and analysis. Adil Mansoor wrote the first draft of the article.

\section{Disclosure statement}

The authors do not have any conflict of interest.

\section{Acknowledgements}

This work was partially supported by the Ilma University, Karachi, Pakistan under the ILMA research grant program. 


\section{References}

Agarwal, U. (2014). Linking justice, trust and innovative work behaviour to work engagement. Personnel Review, 43(1), 4173. https://doi.org/10.1108/PR-02-2012-0019

Al-Ajlouni, M. I. (2020). Can high-performance work systems (HPWS) promote organisational innovation? Employee perspective-taking, engagement and creativity in a moderated mediation model. Employee Relations: The International Journal, 43(2).

https://doi.org/10.1108/ER-09-2019-0369

Amin, M., Till, A., \& McKimm, J. (2018). Inclusive and personcentred leadership: creating a culture that involves everyone. British Journal of Hospital Medicine, 79(7), 402-407. https://doi.org/10.12968/hmed.2018.79.7.402

Ashikali, T., Groeneveld, S., \& Kuipers, B. (2020). The role of inclusive leadership in supporting an inclusive climate in diverse public sector teams. Review of Public Personnel Administration, 41(3). https://doi.org/10.1177/0734371X19899722

Azim, M. T., Fan, L., Uddin, M. A., Abdul Kader Jilani, M. M., \& Begum, S. (2019). Linking transformational leadership with employees' engagement in the creative process. Management Research Review, 42(7), 837-858.

https://doi.org/10.1108/MRR-08-2018-0286

Bakker, A. B., \& Albrecht, S. (2018). Work engagement: current trends. Career Development International, 23(1), 4-11. https://doi.org/10.1108/CDI-11-2017-0207

Carmeli, A., Reiter-Palmon, R., \& Ziv, E. (2010). Inclusive leadership and employee involvement in creative tasks in the workplace: the mediating role of psychological safety. Creativity Research Journal, 22(3), 250-260.

https://doi.org/10.1080/10400419.2010.504654

Cenkci, A. T., Bircan, T., \& Zimmerman, J. (2020). Inclusive leadership and work engagement: the mediating role of procedural justice. Management Research Review, 44(1). https://doi.org/10.1108/MRR-03-2020-0146

Chen, H., Richard, O. C., Dorian Boncoeur, O., \& Ford, D. L. (2020). Work engagement, emotional exhaustion, and counterproductive work behavior. Journal of Business Research, 114, 30-41. https://doi.org/10.1016/j.jbusres.2020.03.025

Choi, S. B., Tran, T. B. H., \& Park, B. Il. (2015). Inclusive leadership and work engagement: mediating roles of affective organizational commitment and creativity. Social Behavior and Personality: An International Journal, 43(6), 931-943. https://doi.org/10.2224/sbp.2015.43.6.931

Fornell, C., \& Larcker, D. F. (1981). Evaluating structural equation models with unobservable variables and measurement error. Journal of Marketing Research, 18(1), 39-50. https://doi.org/10.2307/3151312

Hair, J. F., Sarstedt, M., Ringle, C. M., \& Gudergan, S. P. (2017). Advanced issues in partial least squares structural equation modeling. SAGE Publications. https://doi.org/10.1007/978-3-319-05542-8_15-1

Hakimian, F., Farid, H., Ismail, M. N., \& Nair, P. K. (2016). Importance of commitment in encouraging employees' innovative behaviour. Asia-Pacific Journal of Business Administration, 8(1), 70-83. https://doi.org/10.1108/APJBA-06-2015-0054

Henseler, J., Ringle, C. M., \& Sarstedt, M. (2015). A new criterion for assessing discriminant validity in variance-based structural equation modeling. Journal of the Academy of Marketing Science, 43(1), 115-135.

https://doi.org/10.1007/s11747-014-0403-8
Hollander, E. (2012). Inclusive leadership: The essential leaderfollower relationship. Routledge.

https://doi.org/10.4324/9780203809914

Hughes, D. J., Lee, A., Tian, A. W., Newman, A., \& Legood, A. (2018). Leadership, creativity, and innovation: A critical review and practical recommendations. Leadership Quarterly, 29(5), 549-569. https://doi.org/10.1016/j.leaqua.2018.03.001

Janssen, O. (2000). Job demands, perceptions of effort-reward fairness and innovative work behaviour. Journal of Occupational and Organizational Psychology, 73(3), 287-302. https://doi.org/10.1348/096317900167038

Javed, B., Abdullah, I., Zaffar, M. A., Haque, A. ul, \& Rubab, U. (2019). Inclusive leadership and innovative work behavior: The role of psychological empowerment. Journal of Management \& Organization, 25(04), 554-571. https://doi.org/10.1017/jmo.2018.50

Javed, B., Naqvi, S. M. M. R., Khan, A. K., Arjoon, S., \& Tayyeb, H. H. (2017). Impact of inclusive leadership on innovative work behavior: The role of psychological safety. Journal of Management \& Organization, 23(3), 472. https://doi.org/10.1017/jmo.2017.17

Karatepe, O. M., \& Olugbade, O. A. (2016). The mediating role of work engagement in the relationship between high-performance work practices and job outcomes of employees in Nigeria. International Journal of Contemporary Hospitality Management, 28(10), 2350-2371.

https://doi.org/10.1108/IJCHM-03-2015-0145

Kessel, M., Hannemann-Weber, H., \& Kratzer, J. (2012). Innovative work behavior in healthcare: The benefit of operational guidelines in the treatment of rare diseases. Health Policy, 105(2-3), 146-153.

https://doi.org/10.1016/j.healthpol.2012.02.010

Khan, M. A., Ismail, F. B., Hussain, A., \& Alghazali, B. (2020). The interplay of leadership styles, innovative work behavior, organizational culture, and organizational citizenship behavior. SAGE Open, 10(1). https://doi.org/10.1177/2158244019898264

Kline, R. B. (2015). Principles and practice of structural equation modeling (4th ed.). Guilford Publications. https://books.google.com.my/books?id=Q61ECgAAQBAJ

Lisbona, A., Palaci, F., Salanova, M., \& Frese, M. (2018). The effects of work engagement and self-efficacy on personal initiative and performance. Psicothema, 30(1), 89-96.

Mansoor, A., Farrukh, M., Wu, Y., \& Abdul Wahab, S. (2020). Does inclusive leadership incite innovative work behavior? Human Systems Management, 40(1), 93-102. https://doi.org/10.3233/HSM-200972

Miller, L., \& Miller, A. F. (2020). Innovative work behavior through high-quality leadership. International Journal of Innovation Science, 12(2), 219-236. https://doi.org/10.1108/IJIS-04-2019-0042

Nazir, O., \& Islam, J. U. (2017). Enhancing organizational commitment and employee performance through employee engagement. South Asian Journal of Business Studies, 6(1), 98114. https://doi.org/10.1108/SAJBS-04-2016-0036

Nembhard, I. M., \& Edmondson, A. C. (2006). Making it safe: the effects of leader inclusiveness and professional status on psychological safety and improvement efforts in health care teams. Journal of Organizational Behavior, 27(7), 941-966. https://doi.org/10.1002/job.413

Nitzl, C., Roldan, J. L., \& Cepeda, G. (2016). Mediation analysis in partial least squares path modeling. Industrial Management \& Data Systems, 116(9), 1849-1864. https://doi.org/10.1108/IMDS-07-2015-0302 
Schaufeli, W. B., Bakker, A. B., \& Salanova, M. (2006). The measurement of work engagement with a short questionnaire. Educational and Psychological Measurement, 66(4), 701-716. https://doi.org/10.1177/0013164405282471

Scott, S. G., \& Bruce, R. A. (1998). Following the leader in R\&D: the joint effect of subordinate problem-solving style and leader-member relations on innovative behavior. IEEE Transactions on Engineering Management, 45(1), 3-10. https://doi.org/10.1109/17.658656

Uhl-Bien, M. (2006). Relational Leadership Theory: Exploring the social processes of leadership and organizing. The Leadership Quarterly, 17(6), 654-676. https://doi.org/10.1016/j.leaqua.2006.10.007

Wang, Y., Yang, Y., Wang, Y., Su, D., Li, S., Zhang, T., \& Li, H. (2019). The mediating role of inclusive leadership: Work engagement and innovative behaviour among Chinese head nurses. Journal of Nursing Management, 27(4), 688-696. https://doi.org/10.1111/jonm.12754
Younas, A., Wang, D., Javed, B., \& Konte, A. G. (2020). Inclusive leadership and change-oriented organizational citizenship behavior. In Proceedings of the 2020 4th International Conference on Management Engineering, Software Engineering and Service Sciences (pp. 169-173). https://doi.org/10.1145/3380625.3380652

Zeng, H., Zhao, L., \& Zhao, Y. (2020). Inclusive leadership and taking-charge behavior: roles of psychological safety and thriving at work. Frontiers in Psychology, 11. https://doi.org/10.3389/fpsyg.2020.00062

Zheng, Y., Graham, L., Epitropaki, O., \& Snape, E. (2020). Service leadership, work engagement, and service performance: the moderating role of leader skills. Group \& Organization Management, 45(1), 43-74.

https://doi.org/10.1177/1059601119851978 